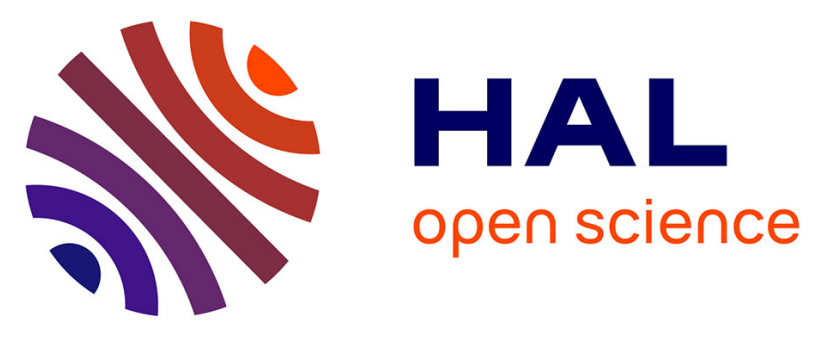

\title{
Taming the Reactivity of Phosphiranium Salts: Site-Selective C-Centered Ring Opening for Direct Synthesis of Phosphinoethylamines
}

Julien Gasnot, Clément Botella, Sébastien Comesse, Sami Lakhdar, Carole Alayrac, Annie-claude Gaumont, Vincent Dalla, Catherine Taillier

\section{To cite this version:}

Julien Gasnot, Clément Botella, Sébastien Comesse, Sami Lakhdar, Carole Alayrac, et al.. Taming the Reactivity of Phosphiranium Salts: Site-Selective C-Centered Ring Opening for Direct Synthesis of Phosphinoethylamines. Angewandte Chemie International Edition, 2020, 59 (29), pp.11769-11773. 10.1002/anie.201916449 . hal-02899688

\section{HAL Id: hal-02899688}

https://hal-normandie-univ.archives-ouvertes.fr/hal-02899688

Submitted on 15 Dec 2020

HAL is a multi-disciplinary open access archive for the deposit and dissemination of scientific research documents, whether they are published or not. The documents may come from teaching and research institutions in France or abroad, or from public or private research centers.
L'archive ouverte pluridisciplinaire HAL, est destinée au dépôt et à la diffusion de documents scientifiques de niveau recherche, publiés ou non, émanant des établissements d'enseignement et de recherche français ou étrangers, des laboratoires publics ou privés. 


\title{
Taming the reactivity of Phosphiranium salts: Site-selective $\mathrm{C}$ centered-Ring Opening for Direct Synthesis of Phosphinoethylamines
}

\author{
Julien Gasnot, ${ }^{[\mathrm{a}]}$ Clément Botella, ${ }^{[\mathrm{a}]}$ Sébastien Comesse, ${ }^{[\mathrm{a}]}$ Sami Lakhdar, ${ }^{[\mathrm{b}]}$ Carole Alayrac, ${ }^{[\mathrm{b}]}$ Annie- \\ Claude Gaumont, ${ }^{[b]}$ Vincent Dalla $^{[\mathrm{a}]^{*}}$ and Catherine Taillier ${ }^{[\mathrm{a}]^{*}}$
}

\author{
[a] Dr. J. Gasnot, C. Botella, Dr. S. Comesse, , Prof. V. Dalla, Dr. C. Taillier \\ Normandie Univ., URCOM, UNIHAVRE, FR 3032, EA 3221, 25 rue P. Lebon, BP 540, 76058 Le Havre (France) \\ E-mail: vincent.dalla@univ-lehavre.fr \\ E-mail: catherine.taillier@univ-lehavre.fr
}

[b] Dr. S. Lakhdar, Dr. C. Alayrac, Prof. A.-C. Gaumont

Normandie Univ., LCMT, ENSICAEN, UNICAEN, CNRS, 6, Boulevard Marechal Juin, 14000 Caen (France)

\begin{abstract}
This work documents advances in the field of phosphorus chemistry, by revealing the synthetic utility of the heretofore under-utilized quaternary phosphiranium salts (QPrS) as 3-chain atoms electrophilic building blocks. Notably, the control of their challenging $\mathrm{C}$-centered electrophilicity is disclosed with as proof of concept an expedient synthesis of tertiary $\beta$-anilino phosphines.
\end{abstract}

The chemistry of 3-membered saturated rings containing one heteroatom has been extensively studied and successfully exploited in many valuable transformations for the rapid and atom-economical access to a wide array of functionalized building blocks. Ring-opening reactions dominate the chemistry of these entities, with epoxides and aziridines as leading examples, and have amply contributed to make them highly valuable and popular synthetic intermediates. ${ }^{[1]}$ Nucleophilic attack is routinely occurring selectively on the ring carbons due to polarization of the C-heteroatom bond, but nonetheless activation of the heterocycles is often required to promote the desired ring cleavage (Scheme 1, A). As seen in the aziridine series, introduction of an electron withdrawing group on nitrogen or quaternarization leading to aziridinium ion intermediates were often used as efficient activation modes to improve reactivity and scope, ${ }^{[2]}$ by weakening the $\mathrm{C}-\mathrm{N}$ bond by accentuating charge separation with concomitant increase of the ring carbons electrophilicity. Despite an obvious structural analogy, 3membered phosphorus analogues have barely been involved in similar transformations, and the site-selective ring opening of phosphirane derivatives at carbon for direct incorporation of phosphino ethylene units into molecules still remains a challenge (Scheme 1, A). This is largely correlated with their relative instability, susceptibility to oxidation, and polarity inversion of the C-P bond which inherently places electrophilicity on phosphorus. ${ }^{[3]-[6]}$ Quaternary phosphiranium salts (QPrS) have long remained elusive species which were mostly described as transient intermediates postulated on the basis of analytical data. ${ }^{[7]}$ The first example of an isolated and fully characterized QPrS dates back to 1995 , and as far as we are aware, only a single report discussing its ring-opening with an external nucleophile is known. ${ }^{[8]}$ Oxygenated nucleophiles $\left(\mathrm{H}_{2} \mathrm{O}\right.$, $\mathrm{MeOH}, \mathrm{EtOH})$ were exclusively used, which not surprisingly (vide supra) led to complete P-selectivity. (Scheme 1, B). Interestingly, one early report presented phosphiranes as potential precursors of polyphosphine polymers using cationic initiation postulated to rely on the formation of a transient phosphiranium intermediate. ${ }^{[6 \mathrm{~b}]}$ On these grounds, we assumed that QPrS are attractive platforms to become useful C-centered 3-chain atoms electrophilic building blocks, by virtue of their broad potential for structural modification and reactivity modulation. In practice, we anticipated that a synergistic association of the required polarity inversion of the P-C linkage to favour C-attack, coupled with an increased steric constrain to prevent nucleophilic attack from occurring at phosphorus, could be fashioned through proper handling of sterics and electronics in a concerted way within the QPrS structures. In this context, we report here preliminary successes toward these aims, illustrated by the first examples of intermolecular ringopenings of phosphiranium salts ${ }^{[9]}$ with good chemical efficiency and complete carbon selectivity using anilines as a nucleophile component (Scheme 1, C).

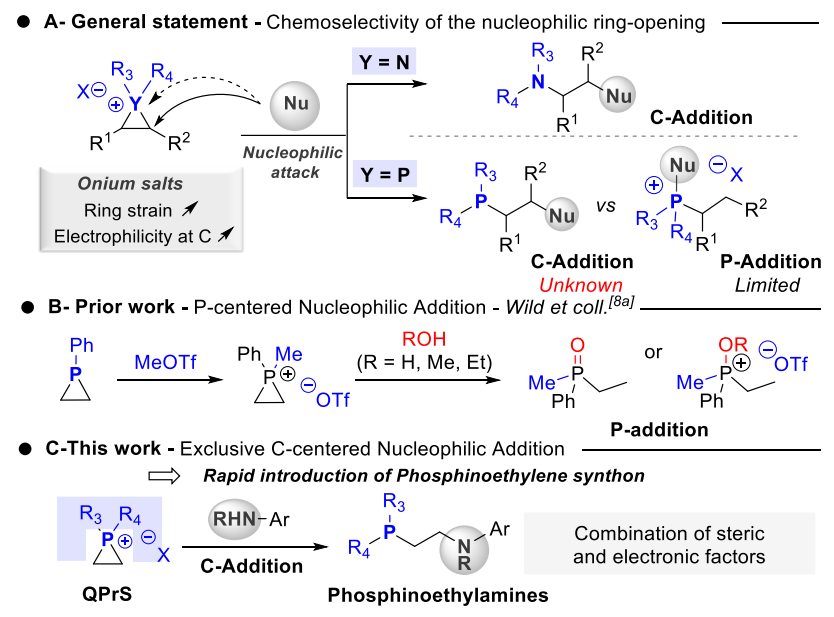

Scheme 1. Nucleophilic ring-opening of nitrogen and phosphorus 3 membered onium ions. 
We began our investigations with the model methylphosphiranium triflate salt 1a. ${ }^{[10],[11]}$ To alleviate any $\mathrm{P}$ affinity issues expressed by the oxygen nucleophiles, ${ }^{[8]}$ we primarily focused our attention on amino derivatives as a nucleophile (Scheme 2). Subjecting phosphiranium salt 1a to an array of primary and secondary amines under various reaction conditions surprisingly either let 1a untouched, or led to the formation of phosphine oxide $\mathbf{5}$ that most likely results from nucleophilic attack at $\mathrm{P}^{[8]}$ and subsequent reaction with water. ${ }^{[12]}$ Use of the less nucleophilic aniline gave rise to a major advance with smooth conversion of 1a and formation of a new major product, which we isolated in pure form ( $84 \%$ yield), and characterized as the desired $\beta$ anilino phosphine 3a ${ }^{[13]}$ A second product was also isolated in $6 \%$ yield and fully characterized as the amino diphosphine 3a' resulting from an additional opening of the phosphiranium 1a by intermediate II. 3a' could be independently prepared and isolated in a synthetically useful yield of $50 \%$ by iterative ring-openings (cond. B). Efforts were undertaken to further optimize the reaction, but the original conditions [Cond. A: phosphiranium 1a (1 equiv), aniline $\mathbf{2 a}$ ( 1 equiv), $\left.\mathrm{CDCl}_{3}, 50{ }^{\circ} \mathrm{C}\right]$ remained the best for optimal yield and selectivity of $\mathbf{3 a} .^{[14]}$

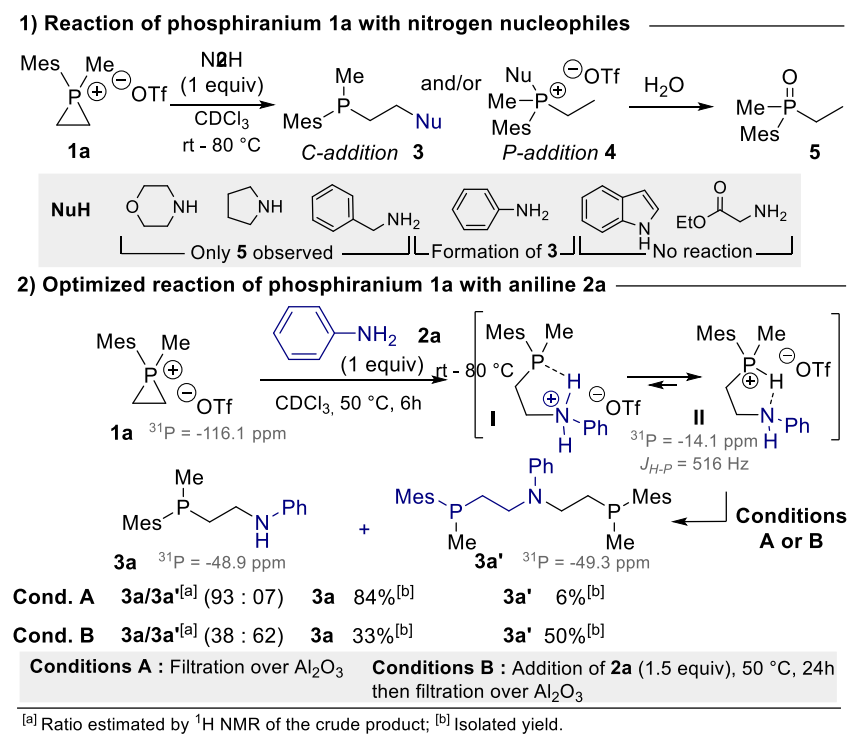

Scheme 2. Nucleophilic ring-opening of phosphiranium cation 1a.

The substrate scope for the ring opening of QPrS 1a was examined using a variety of aniline derivatives (Scheme 3 ). Smooth reactions proceeded with primary anilines $\mathbf{2 a - 2 e}$, providing the corresponding $\beta$-amino phosphines $\mathbf{3 a - 3 e}$. The electronic nature of the substituents on the aromatic ring as well as the steric environment around nitrogen clearly proved to greatly influence reaction kinetics. Reactions indeed took place over an important time range (from $4.5 \mathrm{~h}$ for the electron rich aniline 2c to 4-5 days for bulky (2c) and electronically deactivated anilines $\mathbf{2 d}$ and $\mathbf{2 e}$ ). However, these structural variations did not alter chemical efficiency dramatically, and the desired adducts $\mathbf{3 a - 3 e}$ were isolated in a homogeneous range of $59-84 \%$ yield. Small portions of the corresponding di-addition products 3 ' were typically observed in these reactions, although it should be mentioned that their formation was limited or even suppressed when using electron-poor anilines (see $p-\mathrm{NO}_{2}$ 3d). As an embodiment of the prospective synthetic utility of the method, two bis-phosphinoethylanilines $\mathbf{3 f}$ and $\mathbf{3 g}$ with multiple sites for potential metal coordination. ${ }^{[15]}$ were easily prepared in synthetically useful yields using dianiline nucleophiles $\mathbf{2 f}$ and $\mathbf{2 g}$ (72\% and $41 \%$ yields respectively).

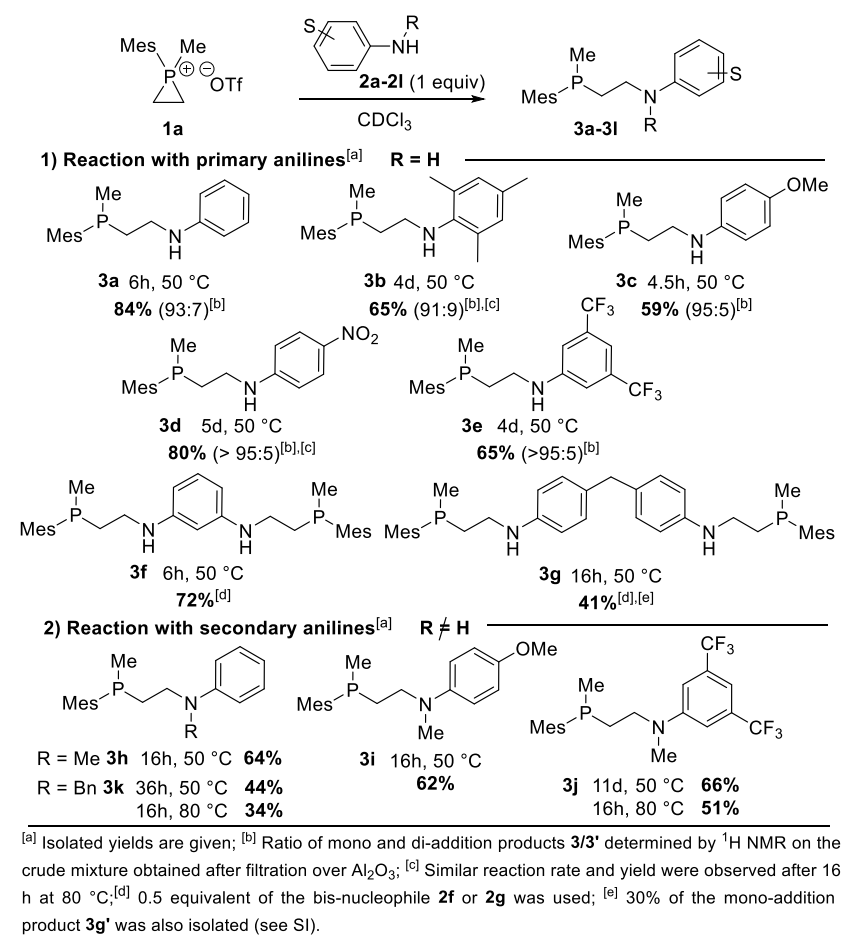

Scheme 3. Nucleophilic ring-opening of phosphiranium cation $1 \mathrm{a}$ with aniline derivatives.

Using standard conditions at $50^{\circ} \mathrm{C}, N$-alkyl secondary anilines $\mathbf{2 h - 2} \mathbf{k}$ gave the corresponding adducts $\mathbf{3 h}-\mathbf{3 k}$ in an uniform and decent range of yields (44-66\%). The data recorded throughout this preliminary set of results demonstrate that both sterics and electronics contribute strongly and almost equitably to reaction rates. As a matter of fact, $\mathrm{N}$-methyl aniline $\mathbf{2 h}$ and its electron-rich 4methoxy analog $2 \mathrm{~g}$ comparatively reacted about 2.5 to 3.5 times slower than their parent primary congeners $\mathbf{2 a}$ and 2c (16 h versus $4.5 \mathrm{~h}-6 \mathrm{~h}$ ). Similarly reactions with $N$ benzyl aniline $\mathbf{2 k}$ and the deactivated $N$-methyl aniline $\mathbf{2} \mathbf{j}$ required further increase of the reaction times (respectively $36 \mathrm{~h}$ and $11 \mathrm{~d}$ ) to reach full conversion. These two amines could, however, be converted within standard reaction time $(16 \mathrm{~h})$ by slightly increasing temperature to $80^{\circ} \mathrm{C}$, with only little erosion on products yields $(\mathbf{3 j}, 51 \%$ versus $66 \%$ and $\mathbf{3 k}, 34 \%$ versus $44 \%$ ).

Modulations of the quaternarizing group $\mathrm{R}$, the arylphosphine group, or the nature of the counteranion, which all are key structural elements within the QPrS structures, [9],[16] were next scrutinized (Scheme 4). Interestingly, both phosphiranium triflate $\mathbf{1 a}$ and tetrafluoroborate $\mathbf{1 b}$ salts exhibited identical outcomes under the optimal reaction conditions with aniline $2 \mathbf{a}$ [2a (1 equiv), $\mathrm{CDCl}_{3}, 50{ }^{\circ} \mathrm{C}, 6.5 \mathrm{~h} \rightarrow \mathbf{3 a}, 84 \%$ and $85 \%$ 
respectively], thus arguing for marginal counteranion effect in this specific case. Furthermore, identical yields of the $\beta$-amino phosphine 3a could also be recorded on application of step-economical one-pot quaternarization/ring-opening sequences starting from the parent mesitylphosphirane and using either MeOTf or $\mathrm{Me}_{3} \mathrm{O} . \mathrm{BF}_{4}$ as methylation agents (see footnote $\mathrm{d}$ in Scheme 4).

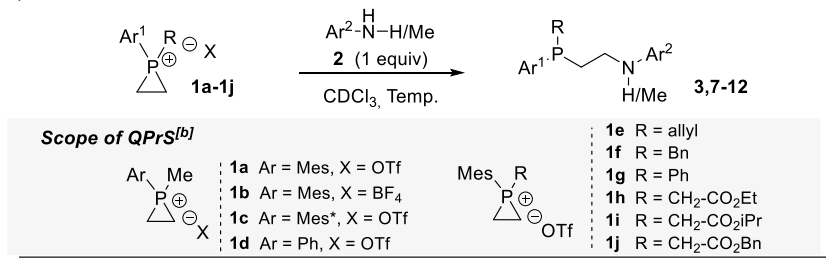

$$
\begin{aligned}
& \text { 1) Reactions with } P \text {-Ar,Me phosphiraniums } 1 a, 1 c-1 d(X=O T f), 1 b\left(X=B F_{4}\right)
\end{aligned}
$$

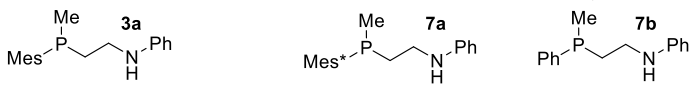

$$
\begin{aligned}
& \begin{array}{c:ccc}
6 \mathrm{~h}, 50^{\circ} \mathrm{C} \text { (from 1a) } & 6.5 \mathrm{~h}, 50^{\circ} \mathrm{C} \text { (from 1b) } & 4 \mathrm{~d}, 50^{\circ} \mathrm{C} \text { (from 1c) } & 6 \mathrm{~h}, 50^{\circ} \mathrm{C} \text { (from 1d) } \\
\mathbf{8 4} \%(93: 07)^{[\mathrm{cc}} & \mathbf{8 5 \%}(93: 07)^{[\mathrm{cc}]} & \mathbf{3 4 \%}(>95: 05)^{[\mathrm{cc}]} & \text { not observed }
\end{array} \\
& \text { One-pot procedure or } 16 \mathrm{~h} 80^{\circ} \mathrm{C} \text { (from 1c) } \\
& 85 \%\left[{ }^{[d]}(92: 08)^{[c]}: \mathbf{8 6}^{[\mathrm{dd}]}(93: 07)^{[\mathrm{cc}} \quad \mathbf{7 7 \%}(>95: 05)^{\mathrm{cl}}\right. \\
& \text { 2) Reactions with P-Mes,alkyl phosphiraniums } 1 \mathrm{e}-1 \mathrm{f}(X=\mathrm{OTf}) \\
& \text { 12h, rt (from 1e) } \\
& \text { 3) Reactions with P-Mes, Ph phosphiraniums } 1 \mathrm{~g}(X=\mathrm{OTf}) \ldots \\
& \begin{array}{c}
3 \mathrm{~h}, 50^{\circ} \mathrm{C}(\text { from } 1 \mathrm{~g}) \\
\mathbf{4 8} \%(82: 18)^{[\mathrm{cc}]}
\end{array}
\end{aligned}
$$

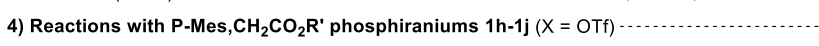

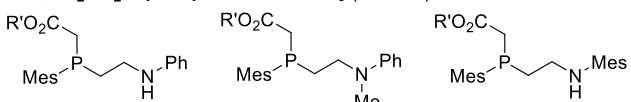

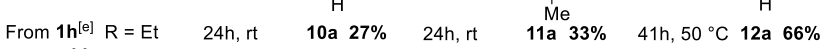

$$
\begin{aligned}
& \text { From } 1 \mathrm{i}^{[e]} \mathrm{R}=i-\mathrm{Pr} \quad 24 \mathrm{~h}, 50{ }^{\circ} \mathrm{C} 10 \mathrm{~b} \quad 48 \% \quad 24 \mathrm{~h}, 50{ }^{\circ} \mathrm{C} \quad 11 \mathrm{~b} \quad 51 \% \quad 24 \mathrm{~h}, 50{ }^{\circ} \mathrm{C} 12 \mathrm{~b} \quad 41 \%
\end{aligned}
$$

Scheme 4. C-centered ring-opening of phosphiranium cations 1a-1j. ${ }^{[a]}$

Influence of steric factors on the reaction selectivity was next evaluated with QPrS 1c and 1d respectively equipped with the bulky supermesityl or the simplest phenyl substituents on P. Reaction of the latter with aniline at $50{ }^{\circ} \mathrm{C}$ only led to side-products. ${ }^{[17]}$ In contrast, the hindered substrate $1 \mathrm{c}$ underwent a slow $\left(4 \mathrm{~d}\right.$ at $\left.50{ }^{\circ} \mathrm{C}\right)$ but productive transformation to afford the corresponding ring-opened product 7a in a modest yield of $34 \%$. Running the reaction at $80{ }^{\circ} \mathrm{C}$ again provided spectacular inputs, with clear reaction kinetic and yield enhancements $(16 \mathrm{~h}, 77 \%)$. The $P$-allyl and $P$-benzyl QPrS 1e, 1f demonstrated a spectacular increase in reactivity on reaction with aniline $\mathbf{2 a}$, yielding in a room temperature process adducts $\mathbf{8 a}$ and $\mathbf{8 b}$ in high yields $(78 \%$ and $71 \%$ over 2 steps $) .{ }^{[16 b]}$

The substrate scope was further extended to P-diarylphosphiranium salt 1g. This latter also exhibited an increased reactivity, since only $3 \mathrm{~h}$ at $50{ }^{\circ} \mathrm{C}(v s 6 \mathrm{~h}$ in the case of the model QPrS 1a) was required for full conversion in reaction with aniline $\mathbf{2 a}$, to give the corresponding ring-opened product $\mathbf{9 a}$ as an inseparable mixture of mono- and di-addition products in a combined isolated yield of $48 \%$ (ratio $=82: 18$ ). This higher reactivity was further exemplified in room temperature reactions with $N$-methyl aniline $\mathbf{2 h}$ and the electron-poor aniline $\mathbf{2 e}$ (which both normally retard the ring-opening, see Scheme 3 ). Both reactions led to the formation of the corresponding ring-opened products $9 \mathbf{b}$ and $9 \mathbf{c}$, within $2.5 \mathrm{~h}$ and $36 \mathrm{~h}$ respectively. However, this increase in reactivity caused an alteration of the ring-opening selectivity, which resulted in moderate yields for the phosphinoethylamine products $9 \mathbf{a}-$ 9c $(38-49 \%)$. ${ }^{[18]}$

The challenging ring-openings of phosphiranium methylene esters $\mathbf{1 h} \mathbf{- 1 j}$ were finally tested with anilines $\mathbf{2 a -}$ $\mathbf{2 b}$ and $\mathbf{2 h}$ to probe the influence of an electronwithdrawing group on both reactivity and regioselectivity. As shown by the formation of phosphinoethyl anilines 10a-10c in the preliminary reactions of $\mathbf{1 h}-\mathbf{1 i}$ with $\mathbf{2 a}$, the $\mathrm{C}$-centered ring-opening still prevailed. In fact, these densely functionalized ester-containing substrates were found to exhibit similar reactivity profile to P-diaryl phosphiranium 1g, with ring-openings proceeding at ambient temperature to give products $\mathbf{1 0 a - 1 0 c}$ in moderate yields (27-48\%). Hypothesizing that the observation of substantial amounts of side products may to some extent reflect site selectivity issues (competition C vs $\mathrm{P}$ ), ${ }^{[19]}$ we next evaluated combination of bulkier reaction partners such as QPrS 1i, 1j and anilines 2b, 2h. As anticipated and delightfully, yield enhancements were observed for the corresponding $\beta$-aminophosphines 11a-11c and 12a-12c which were isolated in $33 \%-88 \%$. ${ }^{[20]}$

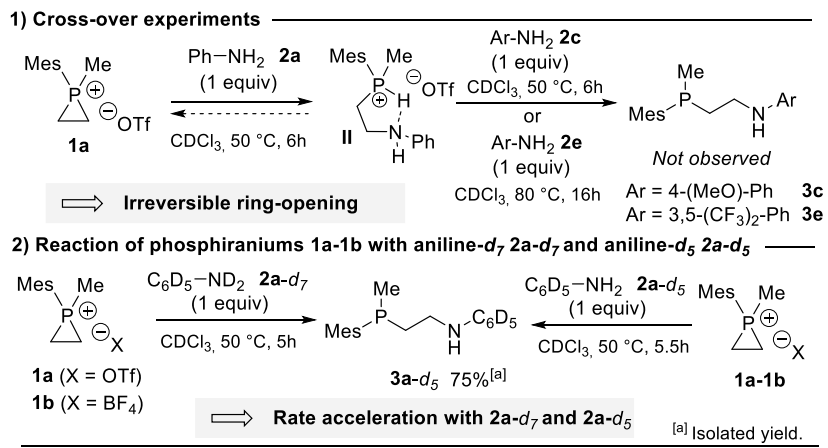

Scheme 5. Mechanistic investigations.

Finally, experiments to gain mechanistic insights into the C-centered ring opening of QPrS 1a were realized (Scheme 5). Since nucleophilic attack of 1a should produce a transient protio-anilinium entity with underlying leaving group ability, the hypothesis of a reversible ringopening operating under thermodynamic control was surveyed. Cross-over experiments reacting the protiophosphonium intermediate II (resulting from a first ring-opening of $\mathbf{1 a}$ with aniline $\mathbf{2 a}$ ) with either $p$-methoxy aniline $\mathbf{2 c}$ or 3,5-diCF 3 aniline $\mathbf{2 e}$ were performed. Neither formation of scrambling products $\mathbf{3 c}$ or $\mathbf{3 e}$ nor back reversion to phosphiranium 1a were observed, thus excluding the occurrence of a reversible process. Otherwise, when evaluating the scope of the reaction, we occasionally observed significant influence of the 
phosphiranium counteranion on the reaction rates (results not shown). We first postulated a possible template effect exerted by the sulfonate group ${ }^{[21]}$ assisting proton transfer from aniline on the forming phosphine during ringopening. Test reactions with aniline- $d_{7} \mathbf{2 a -} d_{7}$ and aniline$d_{5} \mathbf{2} \mathbf{a}-d_{5}$ were thus realized. In both cases, formation of the $\mathrm{NH}$ product 3a- $d_{5}$ was obtained, revealing a H/D exchange during the process. A rather surprising acceleration was also observed with respect to the benchmark reaction, whether starting from the triflate salt $\mathbf{1 a}$ or the tetrafluoroborate salt $\mathbf{1 b}$. These results thus suggest that proton transfer from the developing anilinium ion onto the nascent phosphine is not involved in the rate determining step, thereby arguing for a $S_{N} 2$-type mechanism. ${ }^{[22]}$ Further studies aiming to clarify this assumption are currently ongoing in our laboratory.

In conclusion, the underlying C-centered electrophilicity of phosphiranium ions has been tamed for the first time. Anilines were identified to exhibit the suitable balance of the key nucleophilicity, $\mathrm{pKa}$ and size attributes required to properly control site selectivity in the ring opening of QPrS. This resulted in the production of $\beta$ aminophosphines in fair to good yields, in a straightforward and reliable fashion which complements the few existing routes to these synthetically useful molecules. Beyond the few examples described in this preliminary study, we expect that these results will inspire future discoveries to contribute making QPrS with similar stability and steric features a popular platform for common use in organic synthesis, e.g. to produce dedicated targets, useful building blocks as well as potential P,N-tools for catalysis.

\section{Acknowledgements}

We gratefully acknowledge the region Haute-Normandie, the réseau CRUNCH for grants to JG and CB. JG also thanks the University Le Havre Normandie for financial support.

Keywords: Phosphiranium ions, Nucleophilic ring-opening, Site-selectivity, Steric protection, Phosphinoethyl amines,

[1] a) Aziridines and epoxides in organic synthesis Yudin, A. K. Ed. Wiley-VCH, Weinheim, 2006 ; b) W. H. Pearson, B. W. Lian, S. C. Bergmeier In Comprehensive Heterocyclic Chemistry II; A. R. Katritzky, C. W. Rees, E. F. V. Scriven, Eds.; Pergamon Press: Oxford, 1996; Vol. 1A, Chapter 1, p. 1; c) I. Erden In Comprehensive Heterocyclic Chemistry II; A. R. Katritzky, C. W. Rees, E. F. V. Scriven, Eds.; Pergamon Press: Oxford, 1996; Vol. 1A, Chapter 3, p. 97.

[2] S. Stanković, M. D'hooghe, S. Catak, H. Eum, M. Waroquier, V. Van Speybroeck, N. De Kimpe, H.-J. Ha Chem. Soc. Rev. 2012, 41, 643

[3] a) F. Mathey. Chem. Rev. 1990, 90, 997; b) L. D. Quin, in A Guide to Organophosphorus Chemistry (Ed.: L. D. Quin), John Wiley Sons, New York, 2000, pp. 234-241; c) F. Mathey, M. Regitz, in Phosphorus-Carbon Heterocyclic Chemistry: The Rise of a New Domain (Ed.: F. Mathey), Elsevier Science, Amsterdam, 2001, pp. 17-55.

[4] Phosphiranes are described to be moderately stable species that could lead to ring-fragmentation reactions or rearrangements. For theoretical studies, see: a) J. A. Boatz, M.
S. Gordon, J. Phys. Chem. 1989, 93, 3025; b) Nguyen, M. T.; Landuyt, L.; Vanquickenborne, L. G., J. Chem. Soc, Faraday Trans. 1994, 90, 1771.

[5] Phosphorus and carbon atoms bear significant positive and negative partial charges respectively. a) D. Gonbeau, G Pfister-Guillouzo, Inorg. Chem. 1987, 26, 1799; b) Dobbs, K D.; Boggs, J. E.; Barron, A. R.; Cowley, A. H., J. Phys. Chem. 1988, 92, 4886; c) S.-W. Wang, W. Liu, R. H. Colby Chem. Mater. 2011, 23, 1862.

[6] Only rare examples of three-membered phosphorus ring opening were reported: a) For some examples of phosphiranetungsten complexes $\left[\mathrm{W}(\mathrm{CO})_{5}\right]$ ring-openings, see: A Marinetti, F. Mathey Tetrahedron 1989, 45, 3061. b) For an example of phosphirane cationic ring-opening polymerisation, see: S. Kobayashi, J.-I. Kadokawa, Macromolecular Rapid Communications 1994, 15, 567. c) For some examples of theoretical and experimental studies on phosphirane derivatives ring-openings, see: M. L. Coote, J. L. Hodgson, E. H. Krenske, B. E. Wild Heteroatom Chem. 2007, 18, 118; M. L. Coote, E. H. Krenske, I. Maulana, J. Steinbach, B. E. Wild Heteroatom Chem. 2008, 19, 178.

[7] a) N. J. Lawrence, F. Muhammad J. Chem. Soc., Chem. Commun. 1993, 1187; b) N. J. Lawrence, F. Muhammad, Tetrahedron 1998, 54, 15345; and ibid. 15361 ; c) S. Krupski, G. Kehr, C. G. Daniliuc, G. Erker Chem. Commun. 2016, 52, 2695 and references cited.

[8] a) D. C. R. Hockless, M. A. McDonald, M. Pabel, S. B. Wild J. Chem. Soc., Chem. Commun. 1995, 257; b) D. C. R. Hockless, M. A. McDonald, M. Pabel, S. B. Wild J. Organomet. Chem. 1997, 529, 189; c) For another recent example of isolated QPrS, see: a) A. Ficks, I. Martinez-Botella, B. Stewart, R. W Harrington, W. Clegg, L. J. Higham Chem. Commun. 2011, 47, 8274 .

[9] J. Gasnot, C. Botella, S. Comesse, S. Lakhdar, C. Alayrac, A.C. Gaumont, V. Dalla, C. Taillier, Synlett, 2020, 31, 883.

[10] The model QPrS substrate 1a was obtained by alkylation of the relatively stable parent mesityl phosphirane with methyl triflate. See SI and reference in footnote 9 for details.

[11] QPrS 1a was identified in a preliminary study as presenting the required balance of reactivity/stability for easy handling.

[12] (a) No trace of the desired $\beta$-amino phosphines 3 was detected in any cases; (b) The full scope of nucleophiles tested is given in the SI.

[13] Formation of the protonated intermediate II was first observed, as confirmed by ${ }^{31} \mathrm{P}$ NMR analysis of the crude mixture which gave a broad signal at $-14.1 \mathrm{ppm}$ and a large ${ }^{1} J_{(\mathrm{H}-\mathrm{P})}$ coupling constant $(J=516 \mathrm{~Hz})$. Filtration of the crude mixture over basic $\mathrm{Al}_{2} \mathrm{O}_{3}$ was next performed to release the expected phosphinoethyl amine 3a as the major product (in mixture with the bis-(phosphinoethyl) amine 3a', 3a/3a' = 93:07).

[14] a) The full optimization study is given in the SI; b) It should be noted that identical results in terms of rate and chemical yields were equally obtained using $\mathrm{CDCl}_{3}$ or $\mathrm{CHCl}_{3}$ Consequently, $\mathrm{CDCl}_{3}$ was chosen as solvent of choice for NMR monitoring.

[15] For representative examples of $\mathrm{P}, \mathrm{N}$ - and $\mathrm{P}, \mathrm{N}_{2}$-ligands, see: a) M. P. Carroll, P. J. Guiry Chem. Soc. Rev. 2014, 43, 819; b) W. Li, J. Zhang Chem. Soc. Rev. 2016, 45, 1657; c) For a representative example, see: J. D. G. Correia, A. Domingos, I. Santos Eur. J. Inorg. Chem. 2000, 1523.

[16] a) The corresponding QPrS substrates $\mathbf{1 b - 1 g}$ were obtained from their parent phosphiranes (Conditions A-E, Scheme 4) See SI for details; b) A sequential one-pot triflation/alkylation protocol was applied. For the formation of the sensitive triflate intermediate, see: E. J. Corey, C. J. Helal Tetrahedron Lett. 1996, 37, 5675 .

[17] a) The major product formed in the reaction of phosphiranium 1d was found to be phosphine oxide $\mathbf{5}$ which most likely results from $\mathrm{P}$-addition of either aniline $\mathbf{2 a}$ or water traces. b) 
For similar steric effects observed on the site-selectivity of a $\mathrm{C}$-centered ring opening of epi-selenonium ions, see: A Toshimitsu, K. Nakano, T. Mukai, K. Tamao J. Am. Chem. Soc. 1996, 118, 2756.

[18] In full accordance with our earlier observation (see Scheme 3), formation of the corresponding di-addition products was marginal in the reactions of P-diaryl phosphiranium $\mathbf{1 g}$ with anilines $\mathbf{2 e}$ and $\mathbf{2 h}$.

[19] An increased instability of this series of phosphiranium salts was also observed. As a consequence, storage of the salts $\mathbf{1 h}$ $\mathbf{1 j}$ should be limited to only a few days, even at $-20{ }^{\circ} \mathrm{C}$.
[20] Ratios of mono- and di-addition products not shown - See SI for details.

[21] For leading reviews showcasing counterions templating effect, see: a) H. Xu, S.-J. Zuend, M. G. Woll, Y. Tao, E. N. Jacobsen Science 2010, 327, 986; b) M. Jia, M. Bandini, ACS Catal. 2015, 5, 1638 .

[22] For a relevant kinetic isotope effects study involving deuteriated aniline nucleophiles, see: I. Lee, H. J. Koh, B-S Lee, H. W. Lee, J. Chem. Soc. Chem. Commun. 1990, 335. 